\title{
Post-stroke management research in the light of a rehabilitation scheme aimed at reducing the risk of developing pneumonia
}

\author{
Milena Socha', Maria Kozioł-Montewka², Dariya Popovych³ , Anna Pańczuk² \\ ${ }^{1}$ Fitness Club Olimpia Lublin, Poland \\ 2 Pope John Paul II State School of Higher Education, Biała Podlaska, Poland \\ ${ }^{3}$ Ternopil State Medical University, Ukraine \\ Socha M, Kozioł-Montewka M, Popovych D, Pańczuk A. J Pre-Clin Clin Res. 2018; 12(1): 1-5. doi: 10.26444/jpccr/85127
}

\begin{abstract}
Introduction. Pneumonia is one of the most common infectious complications among people after stroke. The presence of this complication is associated with a significant increase in mortality and a deterioration in the clinical condition of the patients resulting in a longer hospitalization time and more severe rehabilitation, which translates into worse functional status.

Objective. The aim of the study is to analyze the causes and consequences of the development of pneumonia in early post-stroke rehabilitation and to indicate the need for modification of rehabilitation methods at the onset of infection.

Description of the state of knowledge. According to the literature describing infections found in neurological departments and intensive care, the concept of Stroke-associated pneumonia (SAP) is believed to be associated with pneumonia. Risk factors in this situation are disturbances of consciousness and dysphagia, and it is assumed that this condition is associated with abnormal dopamine transmission in patients after extensive stroke.

Conslusion. In the early post-stroke period, there are numerous predictors of pneumonia: dysphagia, decrease in $\mathrm{P}$ levels, cough reflex, adverse bacterial flora development, postprandial immunodepression, mechanical ventilation and hypokinesia, which allow early identification of patients particularly at risk. the risk of disease development and the use of appropriate measures. On the one hand, it points to the need to develop a variety of measures to minimize the risk of developing pneumonia and to rapidly develop new standards of management to improve upon the onset of pneumonia so as to reduce the consequences of infection.
\end{abstract}

\section{Key words}

stroke, rehabilitation, complications, infections

\section{INTRODUCTION}

Brain strokes remain a serious health issue in the Ukraine and Poland. Every 4-5 minutes one person suffers from a stroke and every 16 minutes a patient dies from it. 80$88 \%$ of stroke patients experience an ischemic stroke, the rest $3 / 4$ haemorrhagic stroke. About $29 \%$ of strokes are recurrent [1].

Infections are a common complication in the acute phase of treatment after stroke. Sources report that infectious complications concern from $5 \%$ up to even $65 \%$ of patients, with pneumonia occuring in $1 \%-33 \%$ and urinary tract infection in $2 \%-27 \%$ of patients [2]. Epidemiological predictions indicate that the number of people over the age of 65 will significantly increase in the coming years, which will translate into an increase in stroke incidence and associated infectious complications. Pulmonary inflammation, which contributes to increased mortality due to stroke, prolongs hospitalization, reduces functional improvement, and increases the cost of treatment [3].

Address for correspondence: Milena Socha, Fitness Club Olimpia Lublin, Jana Skrzetuskiego 6/79, 20-628 Lublin, Poland

E-mail: milena.socha@yahoo.com

Received: 7 September 2017; accepted: 8 February 2018

\section{OBJECTIVE}

The aim of the study is to analyze the causes and consequences of the development of pneumonia as a complication during early post-stroke rehabilitation. An additional aim was indication of the need to modify rehabilitation methods at the onset of infection and identification of predators of pneumonia and preventive measures to prevent the development of the disease.

\section{BRIEF STATE OF KNOWLEDGE}

Definition of pneumonia. Stroke-associated pneumonia (SAP) is one of ten described in the literature presenting case studies from neurological departments and intensive care units [4]. This term describes an infection that developes within the first 72 hours after admission. There is also a distinction between acute stroke-related pneumonia, which develops within a month of a stroke, and a chronic form that occurs after a month [5]. Focal pneumonia is a complication in many cases. The disease develops if the local bronchopulmonary defencc weakens and the lung tissue is penetrated, resulting in inflammation in the alveoli, through the bronchi, or less commonly, in the blood or lymphatic systems [6].

Pneumonia has been classified into 3 categories: clinically diagnosed pneumonia, pneumonia caused by commonly 
known bacteria or fungi, or specific laboratory tests, and pneumonia in immunocompromised patients. Clinically defined pneumonia is diagnosed when new or permanent infiltration or consolidation is present on at least one X-ray; additionally, if one of the following clinical symptoms is present: fever, leukopenia or leukocytosis, or altered mental state in over 70-year-olds in the absence of other causes. There can also be new, purulent sputum or a change in the nature of the current sputum, new or worsened existing cough, rales are present and gas exchange deteriorates. Lung inflammation caused by bacteria or fungi is defined similarly. The diagnosis is supplemented by positive blood culture, pleural fluid, quantitative culture of bronchoalveolar lavage or pulmonary parenchyma. The diagnosis is confirmed by one of the symptoms in the form of purulent sputum or cough [4].

\section{THEORIES ABOUT THE CONTRACTION OF PNEUMONIA AFTER STROKE}

Theory of aspiration. It is believed that post-stroke pneumonia is associated with the aspiration of oral contents. Risk factors in this situation are disturbances of consciousness and dysphagia. It is also assumed that this condition is associated with an abnormal transmission of dopamine [6]. Experiments conducted on guinea pigs have shown that blocking dopamine D1 receptors causes a decrease in the release of $P$ substance from the nerve endings and inhibition of swallow reflex. Likewise, low levels of $P$ substance occur in the sputum of the elderly. Angiotensin-converting enzyme inhibitors (ACEI) have been reported to increase $\mathrm{P}$ substance levels and improve the swallowing reflex $[7,8]$.

Decrease in resistance due to stroke. Immunosuppression after stroke is caused by the activation of three systems: the sympathetic, parasympathetic and hypothalamic-pituitaryadrenal axis $[6,7]$. Studies conducted by Prass et al. in mice were intended to explain the effect of immunodeficiency after ischemic stroke on the occurrence of infection. Three days after ischemia, sepsis and pneumonia developed in all tested animals. Stroke caused extensive apoptosis of lymphocytes, change of Th1 helper lymphocytes into Th2 cytokine production, bacteraemia and pneumonia [9]. In the same studies, it was also shown that suppression of sympathetic nervous system activity reduces the risk of bacterial infection and the use of $\beta$-blocker reduces mortality after a stroke. It is caused by a catecholamine-related defect in early lymphocyte activation, and is a key factor in the impaired anti-bacterial immune response after stroke [10]. Activation of the sympathetic nervous system following acute ischemic stroke seems to play a key role in the immunosuppression mechanism particularly evident in patients after extensive stroke [11].

There is also scientific evidence that activation of the hypothalamic-pituitary-adrenal axis causes glucocorticosteroid secretion from the adrenal gland [12]. As glucocorticoids have anti-inflammatory properties, they can cause T lymphocyte apoptosis [13]. Both high and low levels of cortisol circulating in the blood are associated with increased mortality after stroke [12]. Activation of autonomic centres of the parasympathetic system results in cholinergic peripheral cytokine inhibitory activity released by nicotine receptors of macrophages [14]. The neuroendocrine system and autonomic centres are synchronized by periapical hypothalamic centers. The combination of the activities of these systems results in changes in immunity after stroke [15]. This means that stroke-related pneumonia is the sum of existing aspirations that cause the presence of pathogenic bacteria and immunological changes resulting from immunosuppression [9].

Microbiological information. Pneumonia is most often diagnosed during the first days after a stroke [2]. According to microbiological data, it is caused by a hospital infection or acquired aspirate syndrome. Staphylococcus aureus and Gram-negative bacteria, such as Klebsiella pneumoniae, Pseudomonas aeruginosa, Escherichia coli or Enterobacter spp are the most commonly detected strains. Streptococcus strains arei also sometimes identified. Gram-negative bacteria and Staphylococcus aureus cause aspiration pneumonia, but are also known to be infectious, whereas Streptococcus strains are the most commonly detected pathogens in acquired aspirate pneumonia [16, 17].

The material obtained from patients after stroke is usually poor, and additional difficulty in obtaining it is caused by neurological disorders and unconsciousness. Some suspect that pneumonia are actually non-infectious aspirin pneumonia or the infection can be caused by anaerobic bacteria. The role of anaerobic bacteria in the development of pneumonia, however, is inexplainable [18].

A particularly high rate of infection is observed in patients who are in intensive care units afer being diagnosed with severe stroke. In these cases, catheters and mechanical ventilation serve as the infection gates $[19,20]$. The incidence of pneumonia is at $10-25 \%$ [21].

Changes in bacterial flora of patients in intensive care units. Gram-positive bacteria form the majority of the oral mucosal fluids of healthy individuals. These proportions tend to change in subjects staying in intensive care units for longer than 48 hours. At that time, the most prevlent bacteria are: Staphylococcus aureus, Streptococcus pneumoniae, Acinetobacter baumania, Haemophilus influenzae, and Pseudomonas aeruginosa $[22,23]$. Biofilm on the surface of the teeth and tongue and in periodontal disease patients creates optimal conditions for the growth of Gram-negative bacteria, which translates into clinical deterioration of the patients and requires special attention to oral hygiene in this group of patients $[22,23,24]$.

Resistance to antibiotics in Gram-negative bacteria. Gram-negative bacteria are mostly opportunistic, that is, they are the source of infection only in the context of reduced immunity. In addition, they are less sensitive to antibiotics, chemotherapeutics and disinfectants than Grampositive bacteria. This is due to the presence of an additional outer membrane which is an excellent protective barrier. Gram-negative cell enclosures are also equipped with MDR (Multi-drug resistance) systems, which are responsible for removing harmful substances from the inside of the cell including antibiotics, chemotherapeutics and disinfectants. The presence of these pumps is one of the main mechanisms for the acquisition of antibiotic resistance, in addition to antibiotic inactivating enzymes or the ability to alter the structure of proteins at the target site of the antibiotic. 
Lowering the effectiveness of antibiotic therapy due to the increase in resistance among Gram-negative bacteria forces the search for non-pharmacological methods to prevent and treat pneumonia [25].

Clinical status of patients. Another risk factor for developing pneumonia is the clinical condition of patients. The risk of developing infection increases in patients who lack defence reflexes, especially the coughing reflex, and in patients with impaired consciousness [26]. Most cases of pneumonia are due to dysphagia. Literature indicates that swallowing disorders occur in $37-78 \%$ of patients and increase the risk of pneumonia up to 3 -fold [27]. That is why in the literature there are many publications devoted to dysphagia from the aspect of the development of pneumonia due to aspiration of oral contents, which is about $20 \%$ of cases [28]. Stroke and the patient's condition immediately afterwards are therefore the most important predictors of aspiration pneumonia. Among other import ant factors are: dysarthria, hoarseness, volitional disturbances consisting in a weakening cough, and cough after swallowing water.

Aspirated pneumonia has been divided into 2 form due to the chronological occurrence of clinical symptoms: acute pneumonia, which develops before the end of the month, and a chronic or sneaky form that manifests itself later $[5,29]$. Particular attention is paid to the need for screening before feeding the patients. In patients with sudden onset dysphagia (e.g. acute stroke), swallowing screening using screening of aspirants is recommended immediately after admission to the hospital before starting the oral administration of food, fluids or medication. Patients with a positive test result should be given a 'no oral' recommendation (recommended also for medicines) until more thorough neurological diagnosis [30]. An important role is also played by methods of neurostimulation that improve the function of swallowing. For this purpose, stimulation of the peripheral sensory system of the oral and pharynx with chemical, physical or electrical stimuli, and direct stimulation of the throat with the use of repetitive transcranial magnetic stimulation (rTMS), is recommended [28].

Currently available data on the diagnosis and treatment of swallowing disorders and the prevention of pneumonia are still limited, but show that the implementation of therapeutic agents that improve the swallowing function causes a significant reduction in the incidence of disease [31].

Occurrence of infection and age. Long-term predisposing factors for development of the infection is advanced age [32]. Literature reports that the acute phase of post-stroke immunodeficiency and systemic anti-inflammatory immune response are associated with susceptibility to infection [33]. This anti-inflammatory response includes excessive cytokines production and impaired cellular immunity [34].

Infections affect the outcome of treatment after stroke, resulting in poorer functional outcomes and increased mortality. First, infections result in immobilization, general weakness and delayed rehabilitation, which translates into prolonged hospitalization and generates higher costs of treatment [35]. Demographic projections point to a continual increase in the proportion of people aged 65 and over in the European population, which will lead to an increase in the number of people with stroke and the incidence of infections [3].
Influence of infection on ischemic stroke. There are several mechanisms that cause the infection or pneumonia associated with cerebral stroke, which worsen the clinical condition of patients [14]. Pneumonia is associated with fever, electrolyte imbalance and hypoxia. Fever aggravates inflammatory cascades caused by the accumulation of neutrophils in damaged tissue, while hypothermia used as a therapeutic agent modulates the process [36]. Neuronal excitotoxicity caused by increased neurotransmitter and free radicals' release is another mechanism associated with fever resulting in the deterioration of the patient's condition [37]. Electrolyte imbalance, especially hyponatremia, can contribute to increased cerebral oedema following stroke, which translates into increased long-term mortality [38]. The presence of bacteria and liposaccharides in the blood causes blood clotting, as well as activating the fibrinolytic system, which may lead to widening of the ischemia area, and consequently, to an increase in the pneumonia outbreak. This results in deterioration of the patient's condition and reduced recovery.

Forms of treatment and prevention. Stroke affects the work of the respiratory muscles and reduces their strength and cough reflex efficiency by about $50 \%$, compared to healthy people [39]. The method used to treat these disorders is respiratory muscle training (RMT). This training forces the muscles to work harder than during normal functioning, which increases their strength [40]. This type of exercise increases the volume of air inhaled before coughing, which then increases the amount of air flowing during coughing.

According to the literature, a rehabilitation system for patients with focal pneumonia usually includes massage, physical therapy, and exercise therapy using elements of the Strelnikova method of breathing exercises. Analysis of clinical data and results of laboratory tests hale confirmed that patients performing Strelnikova method breathing exercises had better recovery outcomes than patients not using this element in their rehabilitation. Studies show [41] that breathing exercises positively affect metabolism; play an important role in the blood supply, including the lung tissue, improve the drainage function of the bronchi; erase some morphological changes in the bronchopulmonary system (adhesions, sticking processes); encourage resorption of inflammatory nodules; smooth the areas of shriveled tissue and restore normal blood and lymph supply; eliminate local stagnation; and increase the overall resistance. According to the literature, the physical rehabilitation system with the elements of Strelnikova respiratory exercises described by the authors is significantly more effective than the standard programme commonly used in hospitals [41].

The training of respiratory muscles in combination with postural positions draining individual segments of the lungs, frequent change of position and classic breathing exercises prevents lung secretions. Breathing exercises should be used with common sense, remembering to avoid the increased work of the abdominal compressor, as well as hyperventilation in patients with episodes of seizures [42]. Other non-pharmacological prophylaxis measures include elevated body position and reduction in the presence of pathogens of the oral cavity and throat through intense oral hygiene [5, 42]. There are indications that the risk of aspiration pneumonia in patients with swallowing disorders can be reduced by the above-mentioned careful oral hygiene, 
and maintaining a sitting or at least half-sitting position with a backrest $>300$ during the meal and at least 30 minutes thereafter to reduce the risk of reflux. An important role is also played by safe feeding - with small bites and sips, with dense feeding and non-feeding with severe disturbances of consciousness and interruption of feeding when the patient is sleeping, anxious or coughing.

The pharmacological strategies to reduce the incidence of post-stroke pneumonia include preventive administration of antibiotics, ACE inhibitors to increase cough reflex efficiency, and postprandial immunosuppression modification $[5,43]$.

Pneumonia as an impediment to improvement. The occurrence of pneumonia in the early post-stroke period is associated with the need to delay the rehabilitation process. In line with the European Stroke Initiative (EUSI) guidelines, rehabilitation should be started as early as possibile, while still in the stroke ward (from the second day after the neurological event) [44]. All sources underline the importance of starting the rehabilitation process as quickly as possible when the damaged areas of the brain are characterized by the highest plasticity. In the case of ischemic stroke where penumbra is present, this is of particular importance because timely pharmacological treatment and rehabilitation efforts may restore normal functioning of the area, and reduce the extent of necrosis. The development of pneumonia results in delayed initiation of intensive rehabilitation or excludes the use of most of its resources.

Symptoms of infection, such as fever and electrolyte imbalance, are contraindications for classic kinesiotherapy, verticalization and special physiotherapy. It is particularly disadvantageous to delay the introduction of passive exercises chich, in the early stages, prevent the fixation of abnormal motor patterns and the development of mobility limitations [42]. Rapid verticalization is an essential element of functional improvement after stroke because it counteracts thromboembolic complications, muscular atrophy and orthostatic complications. Verticalization is also the moment when control of the sphincter function is usually restored [42]. Postponing the moment of verticalization due to pneumonia is a source of further complications that will translate into worse rehabilitation results, longer hospitalization, and an increased risk of death.

\section{CONCLUSIONS}

The available literature indicates that the occurrence of pneumonia in the early post-stroke period reduces the outcome of later functional improvement and is the most common complication. There are, however, no studies that address the problem of modifying physiotherapeutic agents that affect faster healing at the onset of infection, and the elimination of its effects from the perspective of long-term improvement outcomes.

Numerous studies focus on the early identification of pneumonia predispositions in the form of dysphagia, decrease in $\mathrm{P}$ substancje level, decrease or lack of the gag reflex, adverse bacterial flora development, post-immunodeficiency, mechanical ventilation and hypokinesia, early identification of patients at high risk of developing disease and implemeningt appropriate actions. Such action can have a pharmacological form, the prophylactic administration of antibiotics or ACE inhibitors and non-pharmacological treatment to alleviate the effects of dysphagia, increase oral hygiene, adequate body position and exercises to improve respiratory function.

The increase in stroke incidence has led to the development of various actions aimed at minimizing the risk of developing pneumonia, and the rapid development of new standards of management to improve upon the onset of pneumonia, to reduce the harmful effect of infection on the end result of functional improvement of patients. As a result, the hospitalization time will be shortened, the costs of treatment will decrease and the risk of illness will be reduced.

\section{REFERENCES}

1. Golik VA, Husk AP. Motor Rehab after Stroke. Math. Of Sciences. Practice. Conf. "Carpathian readings": theses of additional. Uzhgorod 2009: 7-8.

2. Westendorp WF, Nederkoorn PJ, Vermeij JD, Dijkgraaf MG, van de Beek D. Post-stroke infection: A systematic review and meta-analysis Westendorp et al. BMC Neurology 2011; 11: 110.

3. Grabowska-Fudula B, Jaracz K, Górna K. Zapadalność, śmiertelność i umieralność z powodu udarów mózgu - aktualne tendencje i prognozy na przyszłość. Prz Epidemiol. 2010; 64: 439-442.

4. Hannawi Y, Hannawi B, Rao CP, Suarez JI, Bershad EM. Strokeassociated pneumonia: major advances and obstacles. Cerebrovasc Dis. 2013 ; 35(5): 430-43.

5. Teramoto $S$. Novel preventive and therapuetic strategy for post-stroke pneumonia. Expert Rev Neurother. 2009; 9: 1187-1200.

6. Avdeev SN, Chuchalin AG. Severe community-acquired pneumonia. Russian Medical Journal. - 2001, 9(5): 177-178.

7. Jia YX, Sekizawa K, Ohrui T, Nakayama K, Sasaki H. Dopamine D1 receptor antagonist inhibits swallowing reflex in guinea pigs. Am J Physiol. 1998; 274: R76-R80.

8. Nakagawa T, Ohrui T, Sekizawa K, Sasaki H. Sputum substance P in aspiration pneumonia. Lancet 1995; 345: 1447.

9. Prass K, Braun JS, Dirnagl U, Meisel C, Meisel A. Stroke propagates bacterial aspiration to pneumonia in a model of cerebral ischemia. Stroke 2006; 37: 2607-2612.

10. Prass K, Meisel C, Hoflich C, et al. Stroke-induced immunodeficiency promotes spontaneous bacterial infections and is mediated by sympathetic activation reversal by poststroke T helper cell type 1 like immunostimulation. J Exp Med. 2003; 198: 725-736.

11. Chamorro A, Meisel A, Planas AM, Urra X, van de Beek D, Veltkamp R. The immunology of acute stroke. Nat Rev Neurol. 2012; 8: 401-410.

12. Marklund N, Peltonen M, Nilsson TK, Olsson T. Low and high circulating cortisol levels predict mortality and cognitive dysfunction early after stroke. J Intern Med. 2004; 256: 15-21.

13. Tuosto L, Cundari E, Gilardini Montani MS, Piccolella E. Analysis of susceptibility of mature human T lymphocytes to dexamethasoneinduced apoptosis. Eur J Immunol. 1994; 24: 1061-1065.

14. Chamorro A, Urra X, Planas AM. Infection after acute ischemic stroke: a manifestation of brain-induced immunodepression. Stroke 2007; 38: 1097-1103.

15. Meisel C, Schwab JM, Prass K, Meisel A, Dirnagl U. Central nervous system injury-induced immune deficiency syndrome. Nat Rev Neurosci. 2005; 6: 775-786.

16. Jones RN. Microbial etiologies of hospital-acquired bacterial pneumonia and ventilator-associated bacterial pneumonia. Clin Infect Dis. 2010; 51(Suppl 1): S81-S87.

17. Bartlett JG. Community-acquired pneumonia. Int J Clin Pract Suppl. 2000, 18-22.

18. Marik PE. Aspiration pneumonitis and aspiration pneumonia. N Engl J Med. 2001; 344: 665-671.

19. Stott D, Falconer A, Miller H, Tilston JC, Langhorne P. Urinary tract infection after stroke. QJM 2009; 102: 243-249.

20. Walter U, Knoblich R, Steinhagen V, Donat M, Benecke R, Kloth A. Predictors of pneumonia in acute stroke patients admitted to a neurological intensive care unit. J Neurol. 2007; 254: 1323-1329.

21. Hilker R, Poetter C, Findeisen N, et al. Nosocomial pneumonia after acute stroke: implications for neurological intensive care medicine. Stroke 2003; 34: 975-981. 
22. Jones DJ, Munro CL, Grap MJ. Natural history of dental plaque accumulation in mechanically ventilated adults: A descriptive correlational study. Intensive Crit Care Nurs. 2011; 27: 299-304.

23. Munro CL, Grap MJ, Elswick RK Jr, McKinney J, Sessler CN, Hummel RS. 3rd Oral health status and development of ventilator-associated pneumonia: A descriptive study. Am J Crit Care 2006; 15: 453-60.

24. Türk G, Kocaçal Güler E, Eser I, Khorshid L. Oral care practices of intensive care nurses: A descriptive study. Int J Nurs Pract. 2012; 18 : 347-53.

25. Laudy AE. Systemy MDR-istotny mechanizm oporności pałeczek Gram-ujemnych na antybiotyki i chemioterapeutyki. Post Mikrobiol. 2008; 47: 415-422.

26. Adnet F, Baud F. Relation between Glasgow Coma Scale and aspiration pneumonia. Lancet 1996; 348: 123-124.

27. Martino R, Foley N, Bhogal S, Diamant N, Speechley M, Teasell R. Dysphagiaafter stroke: incidence, diagnosis, and pulmonary complications. Stroke 2005; 36: 2756-2763.

28. Rofes L, Vilardell N, Clavé P. Post-stroke dysphagia: progress at last. Neurogastroenterol Motil. 2013 Apr; 25(4): 278-82.

29. Lindner-Pfleghar B, Neugebauer H, Stösser S, Kassubek J, Ludolph A, Dziewas R, Prosiegel M, Riecker A. Management of dysphagia in acute stroke: A prospective study for validation of current recommendations. Nervenarzt. 2017 Jan 10. doi: 10.1007/s00115-016-0271-1.

30. Czernuszenko A. Postępowanie w dysfagii neurogennej. Otorynolaryngologia 2016; 15(2): 68-74.

31. Doggett DL, Tappe KA, Mitchell MD, Chapell R, Coates V, Turkelson CM. Prevention of pneumonia in elderly stroke patients by systematic diagnosis and treatment of dysphagia: an evidence-based comprehensive analysis of the literature. Dysphagia. 2001 Fall; 16(4): 279-95.

32. Ovbiagele B, Hills NK, Saver JL, Johnston SC. Frequency and determinants of pneumonia and urinary tract infection during stroke hospitalization. J Stroke Cerebrovasc Dis. 2006; 15: 209-213.
33. Marik PE, Careau P. The role of anaerobes in patients with ventilatorassociated pneumonia and aspiration pneumonia: a prospective study. Chest 1999; 115: 178-183.

34. Emsley HC, Hopkins SJ. Acute ischaemic stroke and infection: recent and emerging concepts. Lancet Neurol. 2008; 7: 341-353.

35. Emsley HC, Smith CJ, Hopkins SJ. Infection and brain-induced immunodepression after acute ischemic stroke. Stroke 2008; 39: e7.

36. Whalen MJ, Carlos TM, Clark RS, et al. The relationship between brain temperature and neutrophil accumulation after traumatic brain injury in rats. Acta Neurochir Suppl. 1997; 70: 260-261.

37. Takagi K, Ginsberg MD, Globus MY, Martinez E, Busto R. Effect of hyperthermia on glutamate release in ischemic penumbra after middle cerebral artery occlusion in rats. Am JPhysiol. 1994; 267: H1770-H1776.

38. Wright WL. Sodium and fluid management in acute brain injury. Curr Neurol Neurosci Rep. 2012; 12: 466-473.

39. Ward K, Seymour J, Steier J, Jolley CJ, Polkey MI, Kalra L, et al. Acute ischaemic hemispheric stroke is associated with impairment of reflex in addition to voluntary cough. Eur Respir J. 2010; 36: 1383-1390.

40. Goldstein RS. Pulmonary rehabilitation in chronic respiratory insufficiency. 3. Ventilatory muscle training. Thorax. 1993; 48: 10251033.

41. Gagar VF, Shevchenko YuA. Physical rehabilitation of patients with focal pneumonia in conditions of permanent establishment. Pedagogics, psychology and medical and biological problems of the physical upbringing and sports 2009; 7: 37-39.

42. Kwolek A. Rehabilitacja neurologiczna, Schorzenia i urazy mózgowia. [w] Rehabilitacja medyczna, Urban \& Partner, Wrocław 2003.

43. Westendorp WF, Vermeij J, Vermeij F, Den Hertog HM, Dippel DWJ, van de Beek D, Nederkoorn PJ. Antibiotic therapy for preventing infections in patients with acute stroke. Cochrane Database Syst Rev. 2012; 1: 008530.

44. Guidelines for Management of Ischaemic Stroke and Transient Ischaemic Attack 2008. Cerebrovasc Dis. 2008; 25: 457-507. 